\title{
A novel homozygous W99G mutation in CLDN-16 gene causing familial hypomagnesemic hypercalciuric nephrocalcinosis in Turkish siblings
}

\author{
Caner Alparslan ${ }^{1}$, Elif Perihan Öncel ${ }^{2}$, Sinem Akbay ${ }^{3}$, Demet Alaygut ${ }^{1}$, Fatma Mutlubaş ${ }^{1}$, \\ Mansur Tatl1 ${ }^{3}$, Martin Konrad ${ }^{4}$, Önder Yavaşcan ${ }^{1}$, Belde Kasap-Demir ${ }^{1,5}$ \\ Departments of ${ }^{1}$ Pediatric Nephrology, ${ }^{2}$ Pediatrics, Izmir Tepecik Training and Research Hospital; Departments of ${ }^{3}$ Neonatal \\ Intensive Care Unit and ${ }^{5}$ Pediatric Nephrology Izmir Katip Çelebi University, Izmir; ${ }^{4}$ Department of General Pediatrics, \\ University Children's Hospital, Münster, Germany; E-mail: caneralparslan@gmail.com \\ Received: 16th March 2017, Revised: 30th May 2017, 16th June 2017, Accepted: 30th June 2017
}

SUMMARY: Alparslan C, Öncel EP, Akbay S, Alaygut D, Mutlubaş F, Tatlı M, Konrad M, Yavaşcan Ö, Kasap-Demir B. A novel homozygous W99G mutation in CLDN-16 gene causing familial hypomagnesemic hypercalciuric nephrocalcinosis in Turkish siblings. Turk J Pediatr 2018; 60: 76-80.

Familial hypomagnesemic hypercalciuric nephrocalcinosis (FHHNC) (OMIM: 248250) is characterized by hypomagnesemia, hypercalciuria and nephrocalcinosis. FHHNC inevitably progresses to end-stage renal disease in decades. Mutations in $C L D N-16$ and $C L D N-19$ genes are associated with disrupted magnesium handling in the thick ascending limp of Henle's loop. Patients with mutations in these genes share similar clinical features, and those with CLDN-19 gene mutations have ocular findings in addition.

A 2-month-old boy, was admitted to our clinic with the complaints of upper respiratory tract infection. He was the first-born child of consanguineous parents. Laboratory findings revealed hypocalcemia and hypomagnesemia. Bilateral medullary nephrocalcinosis was detected on abdominal ultrasound. His ophthalmologic examination was unremarkable. With hypomagnesemia, hypercalciuria and nephrocalcinosis, the patient was considered to have FHHNC. Oral magnessium supplementation was initiated. Four years of follow-up has been completed uneventfully.

When 6-days-old the brother of the case above was admitted with seizure. The patient was resistant to calcium and anticonvulsant drugs and the seizure activity could only be controlled after magnesium infusion. Biochemistry profile revealed hypocalcemia and hypomagnesemia. Urinary calcium extraction was $11 \mathrm{mg} / \mathrm{kg} /$ day. Medullary nephrocalcinosis was reported on renal ultrasound. His eye examination, echocardiography, transfontanel ultrasound and electroencephalography were normal. Due to the triad of hypomagnesemia, hypercalciuria and nephrocalcinosis, and the medical history of his elder brother, he was diagnosed with FHHNC. After correction of the electrolyte abnormalities, he was discharged from hospital and is currently being followedup without any problem.

In this manuscript, we shared our experience about a novel homozygous mutation (W99C) in CLDN-16 gene causing FHHNC in a couple of Turkish siblings.

Key words: nephrocalcinosis, hypomagnesemia, hypercalciuria, children.

Familial Hypomagnesemic Hypercalciuric Nephrocalcinosis (FHHNC) (OMIM: 248250) is a rare autosomal recessive disease with a triad of hypomagnesemia, hypercalciuria and nephrocalcinosis. ${ }^{1}$ In comparison to distal renal tubular acidosis (dRTA), medullary sponge kidney and primary hyperparathyroidism which are also characterized by medullary nephrocalcinosis, FHHNC is a devastating condition leading to end-stage renal disease 
(ESRD). ${ }^{2}$ Mutations in the CLDN genes (CLDN16 and $C L D N-19$ ), encoding renal tight junction proteins (claudin-16 and claudin-19) playing key roles in magnesium handling in the thick ascending limb of Henle's loop, result in FHHNC. Both mutations cause a similar renal phenotype and CLDN19 mutations result in additional ocular involvement. ${ }^{3,4}$ Here, we report a novel homozygous mutation in CLDN16 gene affecting two Turkish siblings.

\section{Case Reports}

\section{Case 1}

A 2-month-old boy, was admitted to our clinic with the complaints of upper respiratory tract infection. He was the first-born child of consanguineous parents (Fig. 1). In his physical examination, body weight was $6.87 \mathrm{~kg}$ (P 7590), height was $60 \mathrm{~cm}$ (P 75-90), and the rest of the physical examination was unremarkable.

Laboratory findings revealed hypocalcemia (initial: $6.8 \mathrm{mg} / \mathrm{dl}$ and control $7.4 \mathrm{mg} / \mathrm{dl}$ ) and hypomagnesemia [1.1 mg/dl (N: 1.5-2.4)]. Other parameters were as follows: serum urea $10 \mathrm{mg} / \mathrm{dl}$, serum creatinine $0.4 \mathrm{mg} / \mathrm{dl}$, potassium $4.57 \mathrm{mmol} / \mathrm{l}$, sodium $136 \mathrm{mmol} / \mathrm{l}$, phosphorus $5.9 \mathrm{mg} / \mathrm{dl}$, serum parathyroid hormone 299.5 $\mathrm{ng} / \mathrm{ml}$ (N: 15-65), 25-OH vitamin D $5.79 \mathrm{ng} /$ $\mathrm{ml}(\mathrm{N}: 20-32)$; urinary calcium/creatinine 1.17 $(\mathrm{N}:<0.4)$, magnesium/creatinine $2.2(\mathrm{~N}: 0.04-$ $1.9 \mathrm{mmol} / \mathrm{mmol}$ ), oxalate/creatinine: 134.62 (N: $5.40-444 \mathrm{mg} / \mathrm{g})$, citrate/creatinine: 1.28 $(\mathrm{N}:>0.51 \mathrm{~g} / \mathrm{g})$, cystine/creatinine: $315.3(\mathrm{~N}$ : $7-54 \mathrm{umol} / \mathrm{mmol}$ ). Also, bilateral medullary nephrocalcinosis was detected on abdominal ultrasound. His ophthalmologic examination was unremarkable. With hypomagnesemia, hypercalciuria and nephrocalcinosis, patient was considered to have FHHNC. Therefore, oral magnesium supplementation was initiated but thiazide treatment could not be given due

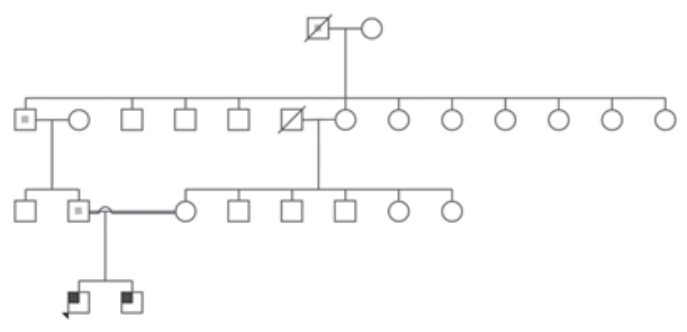

$\square^{-} \square=$

Fig. 1. Pedigree of the family. to unavailability in our country. Four years of follow-up has been completed uneventfully. His last serum creatinine level was $0.8 \mathrm{mg} / \mathrm{dl}$ (GFR:76 ml/min/1.73 $\mathrm{m}^{2}$ ) and he has growing kidneys on ultrasound [Dimensions: right kidney long axis $73 \mathrm{~mm}(\mathrm{~N}$ : $60-80 \mathrm{~mm}$ ) and parenchymal thickness $7 \mathrm{~mm}$; left kidney long axis $76 \mathrm{~mm}(\mathrm{~N}: 60-75 \mathrm{~mm})$ and parenchymal thickness $7 \mathrm{~mm}$ despite persistent medullary nephrocalcinosis] (Fig. 2).

\section{Case 2}

When 6 days old the sibling of the case mentioned above was admitted with seizure. The patient was resistant to calcium and anticonvulsant drugs and the seizure activity could only be controlled after magnesium infusion. He was born by vaginal delivery with a birth weight of $3900 \mathrm{~g}$ to a 24-year-old healthy woman with no history of drug usage. His prenatal history was unremarkable. His weight was $4200 \mathrm{~g}$ (P 90-97), length was $56 \mathrm{~cm}$ (P 97), and head circumference was $37 \mathrm{~cm}$ (P 50-90). His biochemistry profile revealed hypocalcemia (calcium: $6.9 \mathrm{mg} / \mathrm{dl}$ ) and hypomagnesemia (magnesium: $1.2 \mathrm{mg} / \mathrm{dl}$ ). Phosphorus level was $8.9 \mathrm{mg} / \mathrm{dl}$, parathormone level was 106 $\mathrm{pg} / \mathrm{ml}$ (N: 15-65), 25-hydroxy vitamin D level was $5.24 \mathrm{ng} / \mathrm{ml}$. Other parameters were normal. Calcium, magnesium and vitamin D were replaced according to repeated laboratory results. Meanwhile, calcium extraction was $11 \mathrm{mg} / \mathrm{kg} /$ day. Medullary nephrocalcinosis was reported on renal ultrasound. His eye examination, echocardiography, transfontanel ultrasound and electroencephalography were normal. Due to the triad of hypomagnesemia, hypercalciuria and nephrocalcinosis, and the medical history of his elder brother, he was diagnosed with FHHNC. After correction of the electrolyte abnormalities, he was discharged from hospital and is currently being followedup without any problem.

The genetic analysis revealed a new homozygous mutation (W99G) in CLDN16 in both siblings and both parents were for heterozygous for the mutation.

Written informed consent was obtained from family about genetic analysis and publication of the manuscript.

\section{Discussion}

FHHNC is an autosomal recessive disorder 


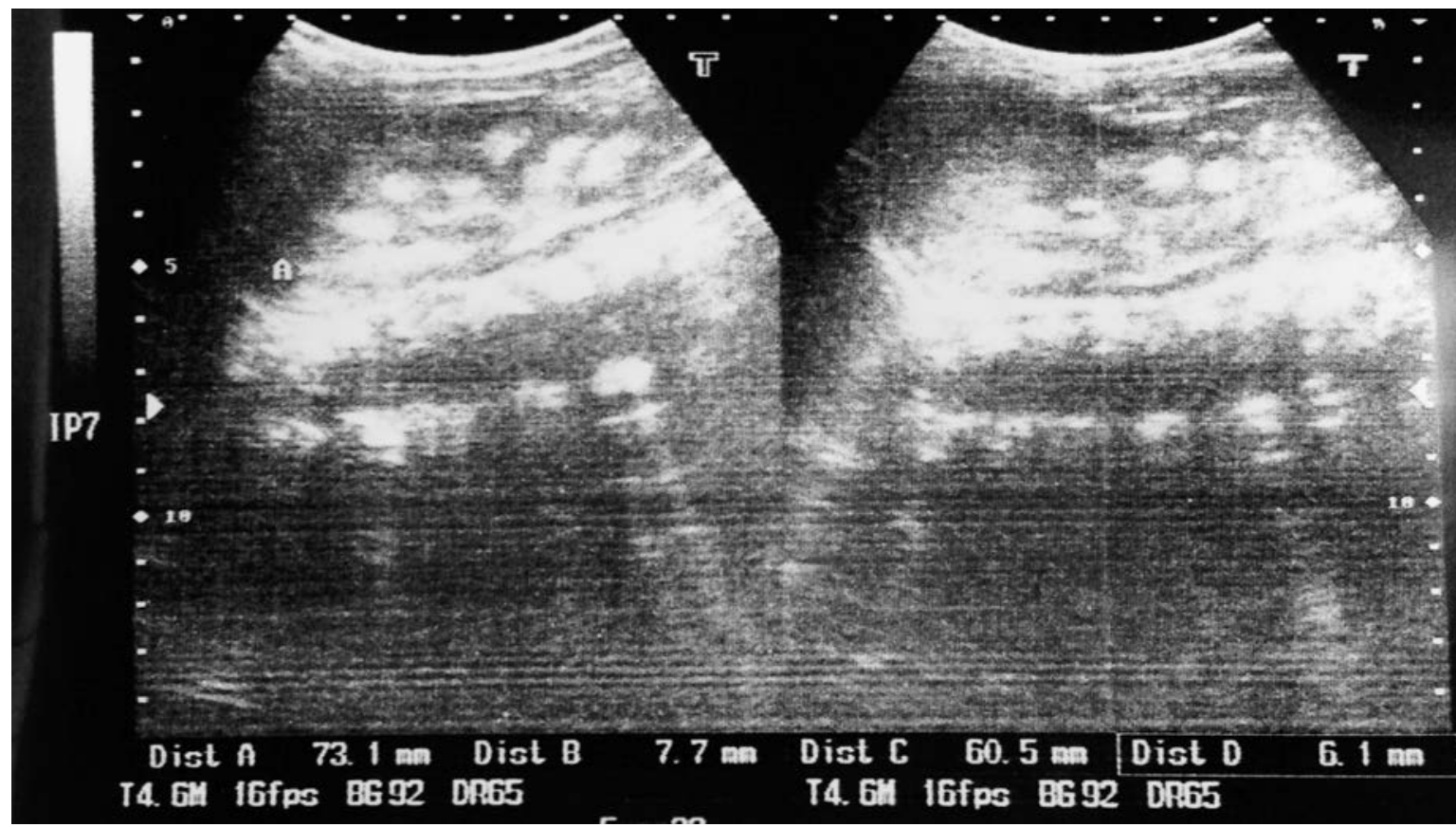

Fig. 2. Bilaterally medullary nephrocalcinosis in kidney ultrasonography.

caused by loss-of-function mutations of genes encoding for tight junction proteins named claudins (16 \& 19) responsible for magnesium and calcium reabsorption in the thick ascending loop of Henle. As a result, hypermagnesiuria, hypomagnesemia, hypercalciuria, hypocalcemia and nephrocalcinosis are seen in patients who have mutations in CLDN16 and CLDN19. As Claudin-19 is also expressed in the retina, mutations in CLDN19 cause additional ocular problems. ${ }^{4}$ We reported two siblings with a new defined homozygous mutation in CLDN16.

Both of our patients had hypermagnesiuria, hypocalcemia and increased parathyroid hormone levels preceding the impairment of GFR in addition to the diagnostic triad and had no ocular problems. These findings suggest a mutation in CLDN16 gene, which is located in chromosome $3 \mathrm{q}$ and consisting of 5 exons. ${ }^{5}$ Various mutations have been identified up till now. The designation of the mutations is: CLDN16 c.295g >t; p.W99G indicating the changes at the nucleotide (c) and protein (p) level (Fig. 3). The amino acid residue is located in the first extracellular loop and the aminoacid exchange changes tryptophane (polar) to a nonpolar aminoacid residue (glycine). These mutations are not assigned in public databases (exome variant server, 100 genomes). In silico prediction judges this variant as pathogenic
(POLYPHEN2 score 0.999).

Patients with FHHNC usually present with recurrent urinary tract infection, polyuria and polydipsia. Additionally, recurrent renal stones, rickets, hematuria, muscular tetany, seizures, failure to thrive, vomiting and abdominal pain may be detected. ${ }^{3-5}$ Our first patient was diagnosed upon incidentally detected hypocalcemia. In the second one, recurrent seizures resistant to treatment due to hypocalcemia and hypomagnesemia in the early neonatal period was the presenting sign. In the neonatal period, maternal diabetes, intrauterine growth restriction, maternal magnesium deficiency, malabsorption syndrome, inherited disorders related to renal wasting magnesiuria secondary to furosemide or aminoglycosides and neonatal hypoparathyroidism can cause hypomagnesemia. ${ }^{6}$ However, neonatal hypomagnesemic convulsion due to FHHNC has not been defined yet. The typical clinical manifestations of hypomagnesemia with secondary hypocalcemia in infants are recurrent generalized convulsions, tetany or irritability. These symptoms are refractory to calcium supplementation and respond only to intravenous or oral magnesium therapy. ${ }^{7} \mathrm{We}$ managed our patient initially with intravenous magnesium (2.5 to $5.0 \mathrm{mg} / \mathrm{kg}$ of elemental magnesium) and then maintained with oral 


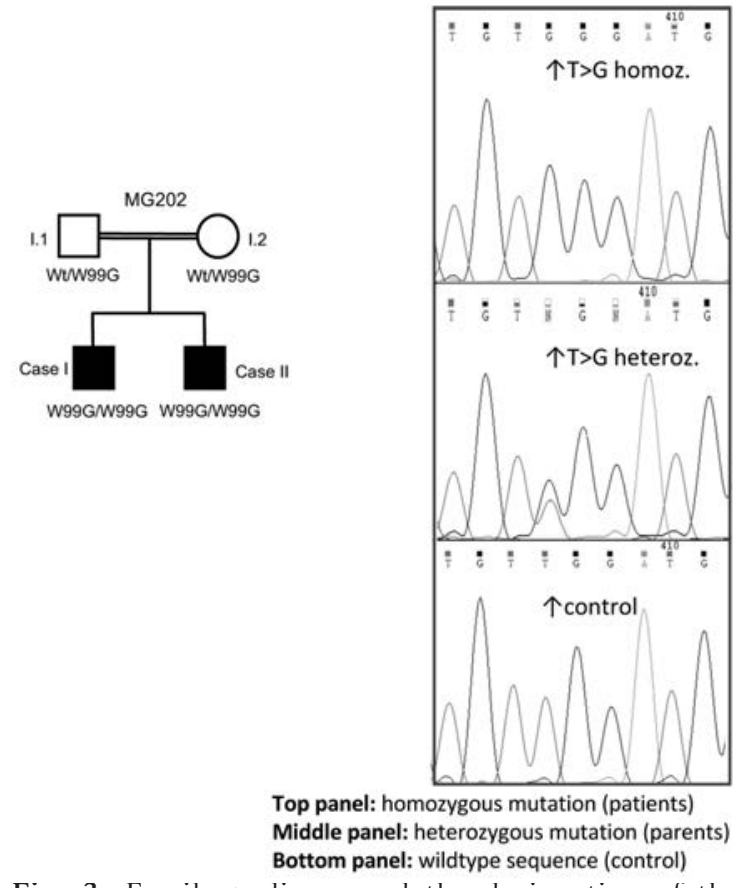

Fig. 3. Family pedigree and the designation of the mutations is: CLDN16 c.295g >t; p.W99G indicating the changes at the nucleotide (c) and protein (p) level.

magnesium oxide supplementation $(25 \mathrm{mg} /$ $\mathrm{kg}$ /day) without any problem. Like neonatal hypomagnesemia, neonatal hypocalcemia is caused by prematurity, fetal growth retardation, infants of diabetic mother, birth aspyhxia, hypoparathyroidisim, syndromes (e.g. DiGeorge syndrome, CATCH), hypomagnesemia, vitamin $\mathrm{D}$ deficiency. ${ }^{8,9}$ Although, neonatal hypocalcemic seizures due to maternal vitamin $\mathrm{D}$ deficiency is not well studied in western societies, symptomatic hypocalcemia without evidence of rickets may present in the early neonatal period. ${ }^{9}, 10$ Hypocalcemia and vitamin $\mathrm{D}$ deficiency may have additive effect in seizures in our patient. After all, we speculate that renal calcium and magnesium wasting is the major pathway for both symptomatic hypocalcemia and hypomagnesemia in our patients.

Medullary nephrocalcinosis was a noteworthy finding in our patients. It may be associated with primary hyperparathyroidism, distal renal tubular acidosis, medullary sponge kidney, hypervitaminosis D, Williams-Beuren syndrome, primary hyperoxaluria, Dent's disease and FHHNC. Among mentioned pathologies, hyperoxaluria, Dent's disease and FHHNC are associated with ESRD., ${ }^{2,3}$ Thus, FHHNC should be considered and other laboratory parameters should be detected while evaluating patients with medullary nephrocalcinosis even in the neonatal period.

In the literature, diagnosis of FHHNC spans a wide range of age. It seems to be clustered at 2-3 years of age. ${ }^{2,4,5,11-16}$ This relatively late age of diagnosis indicates that clinicians are not aware of this entity. Strikingly, our patients were diagnosed in an early period of their lives. As we were familiar with FHHNC because of our previous patients ${ }^{3,14}$, the elder brother was diagnosed when he was 2-months-old and the younger was diagnosed in the postnatal day 6 because of the medical history of his brother. To the best of our knowledge, our second case was the youngest patient diagnosed with FHHNC in the literature.

There is still a debate on whether early diagnosis could alter the disease progression. ${ }^{13,15,16}$ It is known that palliative treatment e.g. magnesium and calcium supplementation, does not have the ability to slow down the disease progression and the definitive treatment of the FHHNC is kidney transplantation. ${ }^{2,4,5,11-16}$ We are planning a close follow-up for our patients.

In conclusion, FHHNC is a rare and devastating disease progressing to ESRD. Practitioners should keep FHHNC in mind in the differential diagnosis of patients with hypocalcemia, hypomagnesemia and medullary nephrocalcinosis and even in the neonates with hypomagnesemic and hypocalcemic convulsions, especially in countries like ours, where consanguineous marriages are common. In addition, we report the youngest case with FHHNC in this paper.

\section{REFERENCES}

1. Tasic V, Dervisov D, Koceva S, Weber S, Konrad M. Hypomagnesemia with hypercalciuria and nephrocalcinosis: case report and a family study. Pediatr Nephrol 2005; 20: 1003-1006.

2. Nadarajah L, Khosravi M, Dumitriu S, et al. A novel claudin-16 mutation, severe bone disease, and nephrocalcinosis. Lancet 2014; 383: 98.

3. Kasap B, Alparslan C, Bal A, et al. Ocular involvement in a child with medullary nephrocalcinosis. Pediatr Nephrol 2013; 28: 627-630.

4. Konrad M, Hou J, Weber S, et al. CLDN16 genotype predicts renal decline in familial hypomagnesemia with hypercalciuria and nephrocalcinosis. J Am Soc Nephrol 2008; 19: 171-181. 
5. Godron A, Harambat J, Boccio V, et al. Familial hypomagnesemia with hypercalciuria and nephrocalcinosis: phenotype-genotype correlation and outcome in 32 patients with CLDN16 or CLDN19 mutations. Clin J Am Soc Nephrol 2012; 7: 801-809.

6. Cole DE, Quamme GA. Inherited disorders of renal magnesium handling. J Am Soc Nephrol 2000; 11:19371947.

7. Abdulrazzaq YM, Smigura FC, Wettrell G. Primary infantile hypomagnesaemia; report of two cases and review of literature. Eur J Pediatr 1989; 148: 459-461.

8. Thomas TC, Smith JM, White PC, Adhikari S. Transient neonatal hypocalcemia: presentation and outcomes. Pediatrics 2012; 129: e1461-1467.

9. Shulman R, O'Gorman CS, Sochett EB. Case 1: Neonate with seizures and hypocalcemia. Paediatr Child Health 2008; 13:197-200.

10. Camadoo L, Tibbott R, Isaza F. Maternal vitamin D deficiency associated with neonatal hypocalcaemic convulsions. Nutr J 2007; 6: 23.
11. Deeb A, Abood SA, Simon J, Dastoor H, Pearce SH, Sayer JA. A novel CLDN16 mutation in a large family with familial hypomagnesaemia with hypercalciuria and nephrocalcinosis. BMC Res Notes 2013; 6: 527.

12. Hampson G, Konrad MA, Scoble J. Familial hypomagnesaemia with hypercalciuria and nephrocalcinosis (FHHNC): compound heterozygous mutation in the claudin 16 (CLDN16) gene. BMC Nephrol 2008; 9: 12.

13. Kang JH, Choi HJ, Cho HY, et al. Familial hypomagnesemia with hypercalciuria and nephrocalcinosis associated with CLDN16 mutations. Pediatr Nephrol 2005; 20: 1490-1493.

14. Peru H, Akin F, Elmas S, Elmaci AM, Konrad M. Familial hypomagnesemia with hypercalciuria and nephrocalcinosis: report of three Turkish siblings. Pediatr Nephrol 2008; 23: 1009-1012.

15. Kari JA, Farouq M, Alshaya HO. Familial hypomagnesemia with hypercalciuria and nephrocalcinosis. Pediatr Nephrol 2003; 18: 506-510.

16. Weber S, Schneider L, Peters M, et al. Novel paracellin-1 mutations in 25 families with familial hypomagnesemia with hypercalciuria and nephrocalcinosis. J Am Soc Nephrol 2001; 12:1872-1881. 